\title{
Polymorphism in FASN, SCD1 and ANXA9 Genes: A Preliminary Study of Markers Which May Serve As Genetic Predictors of the Fatty Acid Profile of Sheep Milk
}

\section{Ewa Pecka-Kietb ( $\nabla$ ewa.pecka@upwr.edu.pl)}

Wroclaw University of Environmental and Life Sciences

Inga Kowalewska-Łuczak

West Pomeranian University of Technology in Szczecin

Ewa Czerniawska-Piątkowska

West Pomeranian University of Technology in Szczecin

Bożena Króliczewska

Wroclaw University of Environmental and Life Sciences

\section{Research Article}

Keywords: sheep, milk, fatty acids, FASN, SCD1, ANXA9

Posted Date: May 28th, 2021

DOl: https://doi.org/10.21203/rs.3.rs-559141/v1

License: (c) (i) This work is licensed under a Creative Commons Attribution 4.0 International License.

Read Full License 


\section{Abstract}

In this study, single nucleotide polymorphisms (SNPs) in the ANXA9 (annexin 9), FASN (fatty acid synthase) and SCD1 (stearoyl-CoA desaturase 1) genes were analyzed as factors influencing fatty acid profiles in milk from Zošl'achtená valaška sheep. SNP in selected genes was identified using polymerase chain reaction (PCR) and restriction fragment length polymorphism (PCR-RFLP). The long-chain fatty acids profile in sheep milk was identified by gas chromatography. Statistical analysis of the SCD1/Cfr13I polymorphism showed that the milk of the homozygous $A A$ animals was characterized by a lower $(\mathrm{P}<$ 0.05) share of $\mathrm{C} 4: 0, \mathrm{C6}: 0, \mathrm{C8}: 0, \mathrm{C} 10: 0, \mathrm{C} 12: 0, \mathrm{C} 14: 0$ in comparison to the homozygous $C C$ sheep. The milk of heterozygous sheep was characterized by a higher $(P<0.05)$ proportion of $C 13: 0$ acid compared to the milk of sheep with the homozygous $A A$ type. A higher $(\mathrm{P}<0.05)$ level of saturated fatty acids (SFA) was found in the milk of $C C$ genotype sheep compared to the $A A$ genotype. Our results lead to the conclusion that the greatest changes were observed for the SCD1/Cfr13I polymorphism and the least significant ones for FASN/ACl. Moreover, it is the first evidence that milk from sheep with SCD1/Cfr13/ polymorphism and the homozygous $A A$ genotype showed the most desirable fatty acids profile.

\section{Introduction}

Globalization and the rapid development of food production have resulted in new consumer food trends. Modern consumers are looking for products rich in valuable nutrients, vitamins and substances that have a positive effect on human health. In food, unsaturated fatty acids have pro-health properties, in particular, they contribute to reducing blood cholesterol ${ }^{1}$. The most desirable fatty acids in the human diet are conjugated linoleic acid (CLA), eicosapentaenoic acid (C20:5n-3, EPA) and docosahexaenoic acid (C22:6n-3, DHA), which play an important role in preventing cancer, cardiovascular, autoimmune, and psychological diseases ${ }^{2}$. In contrast, the SFA intake highly increases coronary disease risk, diabetes, obesity, atherosclerosis, and high low-density lipoprotein (LDL) levels ${ }^{3}$.

Sheep milk is a rich source of unsaturated fatty acids compared to cow and goat milk, which makes it desirable as a functional food ${ }^{4}$. The composition of milk, including the fatty acids profile, is determined by genetic and environmental factors ${ }^{5,6,7}$. The composition of sheep milk is influenced by both genetic and environmental factors. Breed, age and stage of lactation have a significant impact on changes in sheep's milk. The candidate gene approach is applied with regard to genes whose products might affect production traits. Among them, the most extensively studied genes are genes encoding milk proteins (e.g. caseins), hormones and their receptors. Other genes of interest in this area include genes encoding enzymes that participate in fatty acid metabolism as well as genes encoding fatty acid binding and transport proteins ${ }^{8}$.

Fatty acid synthase (FASN) encoded by the FASN gene is a multifunctional homodimeric enzyme that catalyzes the synthesis of fatty acids (FA), plays a key role in the synthesis of short- and medium-chain fatty acids in mammals ${ }^{9,10}$. Additionally, which is important in the adult life of mammals, it determines the energy homeostasis of the organism and is involved in the production of milk lipids during lactation 
11. Annexin 9 (ANXA9) encoded by the $A N X A 9$ gene is a phospholipid and $\mathrm{Ca}^{2+}$ binding protein. It is also involved in the transport across the cytoplasmic membrane, which is important in the mammary gland ${ }^{12}$. On the other hand, stearoyl-CoA desaturase 1 (SCD1) encoded by the SCD1 gene is the key and a ratelimiting enzyme involved in the metabolism of mammary lipids and is responsible for the conversion of SFA into monounsaturated fatty acids (MUFA). Also be a key enzyme in the production of the cis-9, trans11 isomer of conjugated CLA. CLA can be found in ruminant milk and tissue fat and is considered a beneficial effect on human health ${ }^{13,14}$.

Dairy sheep farming systems vary from extensive to intensive according to economic relevance of the production chain and the specific environmental and breed ${ }^{15}$. Only a few publications have comparative values of milk composition for different breeds of sheep and milk energy of sheep breeds, but milk components were not different among breeds ${ }^{15}$.

The available literature data have shown the effects of SNP on the basic composition and protein fractions in sheep milk, however, each variant of the polymorphism was considered separately for each of the FASN, ANXA9 and SCD1 genotypes 7,16,17. Therefore, an attempt was made to determine which of the studied polymorphisms has a more significant impact on the proportion of fatty acids in sheep milk and could be the best candidate marker. Additionally, Zošl'achtená valaška sheep are a local Slovak breed, which opens up prospects for future selection programs and animal protection strategies. For this purpose, this study analyzed SNP polymorphisms in the ANXA9, FASN and SCD1 genes as a factor influencing the fatty acid profile in the milk of Zošl'achtená valaška sheep.

\section{Materials And Methods}

\subsection{Animals and nutrition}

The experiment was carried out in a flock of sheep of the Zošl'achtená valaška a perspective breed, mainly for mountainous areas, which is included in the native Slovak breed. They are bred in the three Slovak regions (Spiš, Orava, and Liptov). The breed was generated by the intentionally combined crossing of Native Wallachian sheep with the rams of various imported breeds as, Cheviot, Hampshire, Lincoln, Texel and Leicester, therefore it is genetically interesting. As a new semi-coarse-wool breed, the Improved Wallachian sheep was recognized in 1982. At present, 128,930 pieces of this breed are kept in Slovakia 18 . Animals of this breed are characterized by good adaptation to difficult mountain conditions. Ewes weigh from 50 to $55 \mathrm{~kg}$, they are seasonally polyoestrous during the fall season (October - November). The composition of mammalian milk is influenced by genetic and environmental factors. Breed, age and stage of lactation have a significant impact on changes in sheep's milk. Therefore, fifty sheep were selected from a herd, taking into account age and lactation stage to eliminate the main variables influencing milk parameters. After lamb weaning, the ewes produced $80-120 \mathrm{~kg}$ of milk during the 150 days of lactation. The material for the study was collected from 50 ewes in the similar phase of milking (25-30 days of lactation) and lactation (1st and 2 nd lactation). In the lambing period, the sheep were kept in special buildings complying with the European Union Directive (No. 116, item 778, 2010) and were fed 
hay ad libitum, $250 \mathrm{~g} / \mathrm{ewe} /$ day of wheat middlings, and $3 \mathrm{~kg} / \mathrm{ewe} /$ day of haylage. To collect milk samples from ewes, their lambs were separated overnight. The milk was collected into sterile containers and transported to the laboratory at $4{ }^{\circ} \mathrm{C}$. Besides, peripheral blood samples were collected from the external jugular vein (EJV) of ewes into test tubes containing anticoagulant (tripotassium ethylenediaminetetraacetic acid, $\mathrm{K}_{3}$ EDTA) for DNA isolation and immediately transported to the laboratory, and frozen at $-20^{\circ} \mathrm{C}$ for subsequent analysis.

DNA isolation was performed using the MasterPure DNA Purification Kit for Blood, Version II (Lucigen, Middleton, WI, USA) according to the manufacturer's instructions. Animal genotyping was performed using PCR-RFLP. Three SNPs in the ANXA9 gene (intron 4, intron 5, GenBank: AY785286.1) and one in the FASN gene (exon 32, GenBank: GQ150557.1) and SCD1 (promoter region, GenBank: FJ513370.1) were analyzed. Table 1 shows the location of individual SNPs and the appropriate primers, designed using the Primer3 software (http://bioinfo.ut.ee/primer3-0.4.0/), enabling the amplification of selected fragments of the analyzed genes. In the case of the reverse primer for the FASN gene, a mismatched nucleotide was introduced to create a cleavage site for the enzyme (this nucleotide is underlined in the Table 1). The polymerase chain reaction (PCR) reaction was performed in a final volume of $25 \mu$, using 2x PCR Master Mix (A\&A Biotechnology, Gdynia, Poland),) containing $50 \mathrm{ng}$ genomic DNA and 5 pmol of each primer. DNA amplification was performed using an initial denaturation at $94^{\circ} \mathrm{C}$ for $5 \mathrm{~min}$, followed by 30 cycles of $30 \mathrm{~s}$ denaturation at $94^{\circ} \mathrm{C}$ each, annealing at a temperature appropriate for each gene for $30 \mathrm{~s}$ and extension at $72^{\circ} \mathrm{C}$ for $30 \mathrm{~s}$, ending with a final extension of 8 minutes at $72^{\circ} \mathrm{C}$ (Table 1$)$.

\section{Table 1. Localization of SNPs and primer sequences for the tested genes.}

\begin{tabular}{|c|c|c|c|}
\hline Gene & Location & Primer Sequence $\left(5^{\prime}-3^{\prime}\right)$ & $\begin{array}{l}\text { Annealing } \\
\text { temperature }\end{array}$ \\
\hline $\begin{array}{l}\text { SCD1 } \\
\text { Chromosome } \\
22\end{array}$ & $\begin{array}{l}\text { promoter region }(31 \\
\mathrm{C}>\mathrm{A})\end{array}$ & $\begin{array}{l}\text { F: } \\
\text { CAGGGGCAGGGGCAGAGGCA } \\
\text { R: } \\
\text { CGCTGGCAGCCGGTGACTGTG }\end{array}$ & $62^{\circ} \mathrm{C}$ \\
\hline $\begin{array}{l}\text { FASN } \\
\text { Chromosome } \\
11\end{array}$ & exon $32(257 \mathrm{C}>\mathrm{T})$ & $\begin{array}{l}\text { F: } \\
\text { TGAGATGGGGCAGCAGGCCT } \\
\text { R: } \\
\text { GGAACACTGTTCGCTTG } \underline{\mathbf{c} G G G}\end{array}$ & $60^{\circ} \mathrm{C}$ \\
\hline $\begin{array}{l}\text { ANXA9 } \\
\text { Chromosome } \\
1\end{array}$ & $\begin{array}{l}\text { intron } 4(\mathrm{c} .172+181 \mathrm{G}> \\
\mathrm{A}) \\
\text { intron } 4(\mathrm{c} .173-27 \mathrm{C}>\mathrm{G}) \\
\text { intron } 5(\mathrm{c} .267+103 \mathrm{C}> \\
\text { A) }\end{array}$ & $\begin{array}{l}\text { F: } \\
\text { CATTCCTGTGTGTCCGGTAC } \\
\text { R: } \\
\text { TCATCTCAGACCTAACCACCA }\end{array}$ & $50^{\circ} \mathrm{C}$ \\
\hline
\end{tabular}

After the amplification of selected fragments of SCD1, FASN and ANXA9 genes, the identification of polymorphic loci in these genes was carried out using appropriately selected restriction enzymes. 
Individual PCR products were digested separately with restriction enzymes according to the manufacturer's recommendations. Next, the restriction fragments were separated on agarose gels with appropriately selected agarose concentration. The restriction enzymes and the obtained restriction fragments for individual genotypes are presented in Table 2 .

Table 2. The size of the restriction fragments for each restriction enzyme of the studied genes.

\begin{tabular}{|llll|}
\hline Gene & Product size (bp) & Restriction enzyme & Size of RFLP band (bp) \\
\hline SCD1 & 225 & Cfr13I & CC: 194,31 \\
& & & CA: $225,194,31$ \\
& & AA: 225 \\
\hline FASN & 275 & Acl & CC: $149,107,19$ \\
& & & CT: $168,149,107,19$ \\
& & & TT: 168,107 \\
ANXA9 & 675 & Nlalll & GG: $252,177,175,71$ \\
& & Hinfl & GA: $252,248,177,175,71$ \\
& & Tru1 & AA: $252,248,175$ \\
& & GG: 366,162147, \\
& & GC: $366,227,162147,139$ \\
& & CC: $227,162,147,139$ \\
& & CC: 450,225 \\
& & CA: $450,389,225,61$ \\
& & AA: $389,225,61$ \\
& &
\end{tabular}

\subsection{Profile of fatty acids}

Fats were extracted from the milk samples using the Folch method [19]. Next, the obtained fat was converted to fatty acid methyl esters using the Christopherson and Glass procedure (1969) [20] with 2M $\mathrm{KOH}$ in methanol. The fatty acid profile was determined, by using a gas chromatography method (Agilent Technologies 7890A, Agilent Technologies, Santa Clara, CA, USA), with a flame ionization detector and an HP-88 capillary column designed for the separation of fatty acid methyl esters (FAMEs) (100 m length, 25 $\mathrm{mm}$ i.d. $\times 0.20 \mu \mathrm{m})$. The initial oven temperature was $50^{\circ} \mathrm{C}$ and was increased by $3^{\circ} \mathrm{C} / \mathrm{min}$ to $220^{\circ} \mathrm{C}$. The detector and dispenser temperatures were $-270^{\circ} \mathrm{C}$ and 270 respectively.

To analyse experimental chromatograms a comparative analysis of the retention times of the fatty acid methyl ester standards [Sigma-Aldrich] was performed using the ChemStation software (Agilent 
Technologies, USA).

\subsection{Statistical analysis}

The frequencies of genotypes and alleles and the Hardy-Weinberg equilibrium for individual SNPs were calculated using the POPGENE software ${ }^{21}$, the effective number of alleles $(\mathrm{Ne})$ was evaluated according to Kimura and Crow (1964) ${ }^{22}$ and expected heterozygosity $(\mathrm{He})$ and the polymorphism information content (PIC) were evaluated according to Nei's methods ${ }^{23}$.

The statistical analysis of the influence of selected SNPs on the fatty acid profile in sheep milk was carried out in the Statistica 13.1 program (StatSoft Poland, Krakow, Poland). The results of the study were statistically analyzed using one-way ANOVA followed by a multiple comparisons Tukey Post-Hoc Test. Pearson correlation coefficient ( $r$ ) with two-tailed test of significance was conducted to examine the relationship between certain parameters.

\section{Results}

The analysis of the obtained genotyping results suggested that for almost all polymorphic loci tested, the presence of all three possible genotypes was identified; only in the FASN gene, two out of three possible genotypes were identified. Table 3 shows the frequencies of genotypes and alleles and the expected heterozygosity, the effective number of alleles, PIC, and the value of $\chi 2$ calculated based on genotyping results.

Table 3. The frequencies of genotypes and alleles for the analyzed SNPs in the studied sheep flock. 


\begin{tabular}{|c|c|c|c|c|c|c|c|c|c|c|}
\hline \multirow[t]{2}{*}{ Polymorphism } & \multirow[t]{2}{*}{$n$} & \multicolumn{2}{|c|}{$\begin{array}{l}\text { Genotype } \\
\text { frequencies }\end{array}$} & \multicolumn{2}{|c|}{$\begin{array}{l}\text { Allele } \\
\text { frequencies }\end{array}$} & \multirow[t]{2}{*}{$\mathrm{He}$} & \multirow[t]{2}{*}{$\mathrm{Ne}$} & \multirow[t]{2}{*}{ PIC } & \multicolumn{2}{|l|}{ HWE } \\
\hline & & & & & & & & & $x^{2}$ & $\begin{array}{l}P \\
\text { value }\end{array}$ \\
\hline \multirow[t]{3}{*}{ SCD1/Cfr13I } & 5 & $A A$ & 0.10 & $A$ & 0.37 & 0.466 & 1.150 & 0.358 & 1.253 & 0.263 \\
\hline & 27 & $A C$ & 0.54 & C & 0.63 & & & & & \\
\hline & 18 & $C C$ & 0.36 & & & & & & & \\
\hline \multirow[t]{3}{*}{ ANXA9/NlallI } & 23 & $G G$ & 0.46 & G & 0.66 & 0.449 & 1.814 & 0.348 & 0.591 & 0.442 \\
\hline & 20 & $G A$ & 0.40 & $A$ & 0.34 & & & & & \\
\hline & 7 & $A A$ & 0.14 & & & & & & & \\
\hline \multirow[t]{3}{*}{ ANXA9/Hinfl } & 22 & \multirow{3}{*}{$\begin{array}{l}G G \\
C G \\
C C\end{array}$} & 0.32 & $G$ & 0.54 & \multirow[t]{3}{*}{0.497} & \multirow[t]{3}{*}{1.987} & \multirow[t]{3}{*}{0.373} & \multirow[t]{3}{*}{14.923} & \multirow[t]{3}{*}{0.0001} \\
\hline & 12 & & 0.44 & C & 0.46 & & & & & \\
\hline & 18 & & 0.24 & & & & & & & \\
\hline \multirow[t]{3}{*}{ ANXA9/ Tru1 } & 18 & $C C$ & 0.36 & $C$ & 0.57 & \multirow[t]{3}{*}{0.490} & \multirow[t]{3}{*}{1.962} & \multirow[t]{3}{*}{0.370} & \multirow[t]{3}{*}{1.025} & \multirow[t]{3}{*}{0.311} \\
\hline & 21 & \multirow{2}{*}{$\begin{array}{l}C A \\
A A\end{array}$} & 0.42 & \multirow[t]{2}{*}{$A$} & \multirow[t]{2}{*}{0.43} & & & & & \\
\hline & 11 & & 0.22 & & & & & & & \\
\hline
\end{tabular}

$\mathrm{n}$ - animal numbers; He - expected heterozygosity; $\mathrm{Ne}$ - effective number of alleles; PIC polymorphic information content, HWE Hardy-Weinberg equilibrium

The expected heterozygosity for almost all examined loci was quite similar and ranged from 0.449 to 0.497; the only exception was the FASN polymorphism where two out of three genotypes were identified. In the case of the effective number of alleles, similar values were observed for most of the analyzed SNPs in the range of 1.814-1.987, except for the SCD1 genes, where this value was 1.150. The PIC value for all tested SNPs was similar and ranged from 0.311 to 0.373 , that according to the classification of Botstein et al. (1980) ${ }^{24}$ indicates an average polymorphism $(0.25<$ PIC value $<0.5)$. The next analyzed parameter was the Hardy-Weinberg equilibrium value (HWE). The distribution of genotypes consistent with the HWE was at $\mathrm{P}>0.05$. The analysis of the results collected in Table 3 shows that the ANXA9/Hinfl polymorphism was found to be incompatible with the Hardy-Weinberg equilibrium. We also assessed the effects of SNPs within the fatty acid synthase gene (FASN), however, we detected only two genotypes $(C C, C T)$ out of $3 F A S N / A c i l$ polymorphism (without $T T$ ). Due to this, we did not calculate HWE for FASN/ACI.

The profile of individual saturated fatty acids in sheep milk in relation to individual genotypes of the studied polymorphisms of the SCD1 and FASN genes is presented in Table 4. Statistical analysis for the $S C D 1 / C F r 131$ polymorphism showed that the milk of individuals with the homozygous $A A$ genotype was characterized by a lower $(P<0.05)$ share of butanoic acid $(C 4: 0)$, hexanoic acid $(C 6: 0)$, octanoic acid 
(C8:0), decanoic acid (C10:0), dodecane (C12:0), tetradecanoate (C14:0) than the homozygous CC sheep. On the other hand, the milk of sheep with the heterozygous genotype was characterized by a higher $(\mathrm{P}<$ 0.05) share of tridecanoic acid (C13:0) as compared to the milk of sheep with the $A A$ genotype. A higher $(P<0.05)$ total level of saturated fatty acids $(S F A)$ was found in the milk of the homozygous $C C$ sheep compared to those of the homozygous $A A$ genotype.

Table 4. The content of individual saturated fatty acids (SFA) in sheep for the SCD1 and FASN polymorphisms.

\begin{tabular}{|c|c|c|c|c|c|}
\hline & \multicolumn{3}{|l|}{ SCD1/Cfr13। } & \multicolumn{2}{|l|}{ FASN/ACI } \\
\hline & $\mathrm{AA}$ & $\mathrm{CA}$ & $\mathrm{CC}$ & $\mathrm{CC}$ & CT \\
\hline \multicolumn{6}{|l|}{ SCFA } \\
\hline $\mathrm{C} 4: 0$ & $0.53 \pm 0.17^{a}$ & $0.54 \pm 0.21$ & $0.67 \pm 0.28^{b}$ & $0.59 \pm 0.23$ & $0.58 \pm 0.29$ \\
\hline $\mathrm{C} 6: 0$ & $0.68 \pm 0.19^{a}$ & $0.75 \pm 0.17$ & $0.85 \pm 0.21^{b}$ & $0.78 \pm 0.19$ & $0.77 \pm 0.21$ \\
\hline C8:0 & $0.81 \pm 0.21^{\mathrm{a}}$ & $0.92 \pm 0.20$ & $1.00 \pm 0.20^{b}$ & $0.94 \pm 0.21$ & $0.95 \pm 0.18$ \\
\hline C10:0 & $2.79 \pm 0.86^{a}$ & $3.25 \pm 0.71$ & $3.45 \pm 0.72^{b}$ & $3.25 \pm 0.76$ & $3.46 \pm 0.55$ \\
\hline Total & $4.80 \pm 1.38$ & $5.47 \pm 1.11$ & $5.96 \pm 1.26$ & $5.77 \pm 1.07$ & $5.56 \pm 1.24$ \\
\hline \multicolumn{6}{|l|}{ LCFA } \\
\hline C12:0 & $1.92 \pm 0.38^{a}$ & $2.15 \pm 0.34$ & $2.31 \pm 0.40^{b}$ & $2.17 \pm 0.40$ & $2.29 \pm 0.16$ \\
\hline C13:0 & $0.03 \pm 0.05^{a}$ & $0.06 \pm 0.02^{b}$ & $0.05 \pm 0.02$ & $0.05 \pm 0.03$ & $0.07 \pm 0.02$ \\
\hline C14:0 & $7.22 \pm 0.65^{\mathrm{a}}$ & $7.74 \pm 0.81$ & $8.18 \pm 0.89^{b}$ & $7.83 \pm 0.91$ & $8.01 \pm 0.59$ \\
\hline C15:0 & $1.10 \pm 0.19$ & $1.09 \pm 0.19$ & $1.12 \pm 0.06$ & $1.07 \pm 0.16$ & $1.16 \pm 0.19$ \\
\hline $\mathrm{C} 16: 0$ & $21.44 \pm 0.95$ & $22.03 \pm 1.15$ & $21.81 \pm 1.44$ & $21.90 \pm 1.29$ & $21.89 \pm 1.02$ \\
\hline $\mathrm{C} 17: 0$ & $1.09 \pm 0.08$ & $1.01 \pm 0.11$ & $1.01 \pm 0.12$ & $1.03 \pm 0.11$ & $0.98 \pm 0.10$ \\
\hline C18:0 & $12.61 \pm 0.16$ & $11.48 \pm 1.41$ & $12.33 \pm 1.74$ & $11.91 \pm 1.58$ & $11.83 \pm 1.31$ \\
\hline $\mathrm{C} 20: 0$ & $0.31 \pm 0.04$ & $0.32 \pm 0.04$ & $0.33 \pm 0.06$ & $0.32 \pm 0.05$ & $0.34 \pm 0.05$ \\
\hline Total & $45.70 \pm 1.64$ & $45.88 \pm 2.13$ & $47.08 \pm 1.19$ & $46.55 \pm 1.33$ & $46.27 \pm 1.95$ \\
\hline \SFA\% & $50.49 \pm 2.85^{a}$ & $51.32 \pm 2.85$ & $53.02 \pm 1.84^{b}$ & $51.80 \pm 2.71$ & $52.30 \pm 2.27$ \\
\hline
\end{tabular}

SCFA- short-chain fatty acids, LCFA - long-chain fatty acids, SFA - saturated fatty acids. Mean \pm SD values within the same row sharing a different superscript letter $(a, b, c$, etc.) are significantly different 
$(P<0.05)$.

Table 5 presents the share of unsaturated fatty acids in sheep milk in relation to the studied polymorphisms of the $S C D 1$ and $F A S N$ genes. The analysis of the SCD1/CFr13I polymorphism revealed that the proportion of ( $\mathrm{Z}$-11-eicosenoic acid $(C 20: 1)$ in milk was lower $(P<0.05)$ in the homozygous $A A$ sheep in relation to the heterozygous and homozygous $C C$ individuals. Higher $(P<0.05)$ levels of MUFA were noted in the homozygous $A A$ individuals compared to the homozygous $C C$ individuals. The relationship for all cis-5,8,11,14,17-eicosapentaenoic acid (C20:5n3) was reverse: in the milk of the homozygous $A A$ sheep the level of this acid was lower $(\mathrm{P}<0.05)$ compared to individuals with the $C C$ genotype. The polymorphism in the FASN gene will not statistically affect the fatty acid profile in sheep milk. For the remaining saturated and saturated fatty acids in milk, no statistical effect of polymorphisms for the SCD1 gene was observed.

Table 5. The content of individual unsaturated fatty acids (UFA) in sheep milk for the SCD1 and FASN polymorphisms. 


\begin{tabular}{|llllll|}
\hline & SCD1/Cfr13I & & \multicolumn{3}{l|}{ FASN/ACI } \\
\hline MUFA & AA & CA & CC & CC & CT \\
\hline C14:1 & $0.53 \pm 0.15$ & $0.57 \pm 0.09$ & $0.56 \pm 0.08$ & $0.56 \pm 0.09$ & $0.62 \pm 0.08$ \\
\hline C16:1 & $5.63 \pm 0.66$ & $5.78 \pm 0.73$ & $5.44 \pm 0.64$ & $5.59 \pm 0.69$ & $5.93 \pm 0.75$ \\
\hline C17:1 & $0.53 \pm 0.08$ & $0.50 \pm 0.06$ & $0.49 \pm 0.06$ & $0.50 \pm 0.06$ & $0.48 \pm 0.06$ \\
\hline C18:1n9c & $23.57 \pm 1.35$ & $22.75 \pm 2.31$ & $21.85 \pm 1.67$ & $22.66 \pm 2.16$ & $21.51 \pm 0.94$ \\
\hline C18:1n9t & $1.92 \pm 0.51$ & $1.84 \pm 0.37$ & $1.88 \pm 0.49$ & $1.85 \pm 0.37$ & $1.94 \pm 0.66$ \\
\hline C18:1n7t & $2.27 \pm 0.19$ & $2.15 \pm 0.27$ & $2.06 \pm 0.27$ & $2.13 \pm 0.28$ & $2.09 \pm 0.23$ \\
\hline C20:1 & $0.06 \pm 0.04^{\mathrm{a}}$ & $0.08 \pm 0.03^{\mathrm{b}}$ & $0.08 \pm 0.02^{\mathrm{b}}$ & $0.08 \pm 0.03$ & $0.08 \pm 0.02$ \\
\hline $\boldsymbol{\Sigma}$ MUFA & $34.51 \pm 2.00^{\mathrm{b}}$ & $33.66 \pm 2.29$ & $32.36 \pm 1.60^{\mathrm{a}}$ & $32.63 \pm 1.24$ & $33.36 \pm 2.24$ \\
\hline PUFA & & & & & \\
\hline C18:2n6c & $1.91 \pm 0.33$ & $1.76 \pm 0.29$ & $1.77 \pm 0.23$ & $1.78 \pm 0.27$ & $1.74 \pm 0.31$ \\
\hline CLA & $1.29 \pm 0.12$ & $1.25 \pm 0.27$ & $1.19 \pm 0.15$ & $1.24 \pm 0.23$ & $1.22 \pm 0.18$ \\
\hline C18:3n3 & $1.46 \pm 0.08$ & $1.53 \pm 0.23$ & $1.48 \pm 0.19$ & $1.53 \pm 0.21$ & $1.35 \pm 0.10$ \\
\hline C20:4n6 & $0.10 \pm 0.07$ & $0.11 \pm 0.03$ & $0.10 \pm 0.02$ & $0.10 \pm 0.03$ & $0.12 \pm 0.04$ \\
\hline C20:5n3 & $0.07 \pm 0.05^{\mathrm{a}}$ & $0.08 \pm 0.02$ & $0.09 \pm 0.02^{\mathrm{b}}$ & $0.08 \pm 0.03$ & $0.08 \pm 0.02$ \\
\hline $\boldsymbol{\Sigma}$ PUFA & $4.82 \pm 0.40$ & $4.72 \pm 0.66$ & $4.62 \pm 0.45$ & $4.49 \pm 0.44$ & $4.73 \pm 0.59$ \\
\hline $\boldsymbol{\Sigma}$ UFA & $40.14 \pm 1.73$ & $39.17 \pm 2.61$ & $37.74 \pm 1.73$ & $38.87 \pm 2.49$ & $37.92 \pm 1.23$ \\
\hline
\end{tabular}

MUFA - monounsaturated fatty acids, PUFA - Polyunsaturated fatty acids. Mean \pm SD values within the same row sharing a different superscript letter $(a, b, c, e t c$.$) are significantly different (P<0.05)$.

The analysis of the share of short- and long-chain saturated fatty acids with respect to the individual genotypes of the studied polymorphisms in the ANXA9 gene is presented in Table $6(\mathbf{a}, \mathbf{b}, \mathbf{c})$. Statistical analysis for the ANXA9/Hinfl polymorphism showed that the milk of individuals with the homozygous $C C$ genotype was characterized by a higher $(P<0.05)$ content of pentadecanoic acid $(C 15: 0)$ and eicosanoic acid (C20:0) than the milk of heterozygous sheep. In contrast, the milk of sheep with the $C G$ genotype was characterized by a lower $(P<0.05)$ proportion of octadecanoic acid $(C 18: 0)$ compared to the milk of sheep with the homozygous $G G$ genotype. For the remaining saturated fatty acids in milk, no statistical effect of $A N X A 9$ polymorphisms was observed. 
Table 7 (a, b, c) shows the contribution of UFA in Zošl'achtená valaška milk with respect to individual genotypes of the ANXA9 polymorphisms examined in this study. Analysis of the ANXA9/N/all polymorphism showed that the share of (all-Z) -5,8,11,14-eicosatetraenoic acid (20:4n6) in milk was lower $(\mathrm{P}<0.01)$ in the sheep with the homozygous $A A$ genotype in relation to individuals with heterozygous and homozygous $G G$ genotypes. In the case of the $A N X A 9 /$ Hinfl polymorphism, it was shown that the milk of sheep with the homozygous $G G$ genotype was characterized by a higher proportion of transoctadecenoic acid (C18:1n9t) compared to the homozygous $C C(P<0.01)$ and heterozygous $(P<0.05)$ sheep. Also, a higher $(P<0.05)$ share of CLA was found in the homozygous $G G$ individuals compared to heterozygous ones. For the $A N X A 9 / T r u 11$ polymorphism, it was found that animals with the homozygous $A A$ genotype were characterized by a lower $(\mathrm{P}<0.05)$ proportion of $\mathrm{C} 18: 1 \mathrm{n} 9 \mathrm{t}$ acid in milk compared to heterozygous sheep and higher $(P<0.05)$ compared to the homozygous $C C$ animals. The polymorphism in the ANXA9 gene did not statistically affect the share of other unsaturated fatty acids in sheep milk.

Table 6. The content of individual saturated fatty acids (SFA) in the milk of the Zošl'achtená valaška sheep for the ANXA9 polymorphisms. a) ANXA9/Nlalli, b) ANXA9/Hinfl, c) ANXA9/Tru1/

6 a) 


\begin{tabular}{|llll|}
\hline \multicolumn{4}{|c|}{ ANXA9/Nlall } \\
& AA & GA & GG \\
\hline SCFA & & & \\
\hline C4:0 & $0.46 \pm 0.20$ & $0.64 \pm 0.29$ & $0.57 \pm 0.18$ \\
\hline C6:0 & $0.68 \pm 0.19$ & $0.83 \pm 0.20$ & $0.77 \pm 0.17$ \\
\hline C8:0 & $0.82 \pm 0.20$ & $0.98 \pm 0.19$ & $0.94 \pm 0.21$ \\
\hline C10:0 & $2.87 \pm 0.78$ & $3.38 \pm 0.64$ & $3.31 \pm 0.78$ \\
\hline Total & $4.83 \pm 1.14$ & $5.21 \pm 1.11$ & $5.59 \pm 1.20$ \\
\hline LCFA & & & \\
\hline C12:0 & $2.03 \pm 0.36$ & $2.23 \pm 0.30$ & $2.20 \pm 0.44$ \\
\hline C13:0 & $0.06 \pm 0.03$ & $0.05 \pm 0.02$ & $0.05 \pm 0.03$ \\
\hline C14:0 & $7.98 \pm 1.12$ & $7.84 \pm 0.80$ & $7.84 \pm 0.89$ \\
\hline C15:0 & $1.13 \pm 0.16$ & $1.09 \pm 0.18$ & $1.06 \pm 0.16$ \\
\hline C16:0 & $22.59 \pm 1.19$ & $21.81 \pm 1.26$ & $21.79 \pm 1.23$ \\
\hline C17:0 & $1.03 \pm 0.09$ & $1.03 \pm 0.11$ & $1.00 \pm 0.11$ \\
\hline C18:0 & $11.74 \pm 0.98$ & $12.22 \pm 1.78$ & $11.65 \pm 1.43$ \\
\hline C20:0 & $0.33 \pm 0.05$ & $0.33 \pm 0.05$ & $0.31 \pm 0.05$ \\
\hline Total & $46.87 \pm 2.02$ & $46.58 \pm 1.71$ & $45.88 \pm 1.82$ \\
\hline $\boldsymbol{\Sigma}$ SFA\% & $\mathbf{5 1 . 6 9} \pm 3.28$ & $52.39 \pm 2.36$ & $51.46 \pm 2.72$ \\
\hline & & & \\
\hline
\end{tabular}

SCFA- short-chain fatty acids, LCFA - long-chain fatty acids, SFA - saturated fatty acids; (g/ $100 \mathrm{~g}$ of fat). Mean $\pm S D$ values within the same row sharing a different superscript letter $(a, b, c, e t c$.) are significantly different $(P<0.05)$.

6 b) 


\begin{tabular}{|c|c|c|c|}
\hline & \multicolumn{3}{|l|}{ ANXA9/Hinfl } \\
\hline & $\mathrm{CC}$ & CG & GG \\
\hline \multicolumn{4}{|l|}{ SCFA } \\
\hline C4:0 & $0.63 \pm 0.27$ & $0.53 \pm 0.18$ & $0.63 \pm 0.27$ \\
\hline C6:0 & $0.83 \pm 0.21$ & $0.76 \pm 0.19$ & $0.77 \pm 0.17$ \\
\hline C8:0 & $0.97 \pm 0.21$ & $0.95 \pm 0.22$ & $0.91 \pm 0.19$ \\
\hline C10:0 & $3.36 \pm 0.70$ & $3.36 \pm 0.79$ & $3.13 \pm 0.71$ \\
\hline Total & $5.78 \pm 1.26$ & $5.60 \pm 2.27$ & $5.36 \pm 1.11$ \\
\hline \multicolumn{4}{|l|}{ LCFA } \\
\hline C12:0 & $2.23 \pm 0.32$ & $2.23 \pm 0.42$ & $2.11 \pm 0.36$ \\
\hline C13:0 & $0.06 \pm 0.01$ & $0.05 \pm 0.03$ & $0.05 \pm 0.03$ \\
\hline $\mathrm{C} 14: 0$ & $8.02 \pm 0.95$ & $7.91 \pm 0.83$ & $7.66 \pm 0.86$ \\
\hline C15:0 & $1.17 \pm 0.15^{b}$ & $1.04 \pm 0.17^{a}$ & $1.07 \pm 0.17$ \\
\hline C16:0 & $22.36 \pm 1.42$ & $22.07 \pm 0.91$ & $21.31 \pm 1.30$ \\
\hline $\mathrm{C} 17: 0$ & $1.04 \pm 0.10$ & $0.98 \pm 0.11$ & $1.05 \pm 0.10$ \\
\hline C18:0 & $11.80 \pm 1.78$ & $11.29 \pm 1.03^{a}$ & $12.74 \pm 1.56^{b}$ \\
\hline $\mathrm{C} 20: 0$ & $0.34 \pm 0.04^{b}$ & $0.30 \pm 0.04^{a}$ & $0.33 \pm 0.05$ \\
\hline Total & $47.01 \pm 2.09$ & $45.87 \pm 15.91$ & $46.20 \pm 1.61$ \\
\hline$\Sigma$ SFA\% & $52.79 \pm 2.65$ & $51.47 \pm 2.86$ & $51.72 \pm 2.27$ \\
\hline
\end{tabular}

SCFA- short-chain fatty acids, LCFA - long-chain fatty acids, SFA - saturated fatty acids; ( $\mathrm{g} / 100 \mathrm{~g}$ of fat). Mean \pm SD values within the same row sharing a different superscript letter $(a, b, c$, etc.) are significantly different $(P<0.05)$.

$6 c)$ 


\begin{tabular}{|c|c|c|c|}
\hline & \multicolumn{3}{|l|}{ ANXA9/Tru1I } \\
\hline & AA & CA & $\mathrm{CC}$ \\
\hline \multicolumn{4}{|l|}{ SCFA } \\
\hline $\mathrm{C} 4: 0$ & $0.58 \pm 0.21$ & $0.58 \pm 0.25$ & $0.63 \pm 0.27$ \\
\hline C6:0 & $0.79 \pm 0.19$ & $0.78 \pm 0.20$ & $0.77 \pm 0.17$ \\
\hline C8:0 & $0.97 \pm 0.21$ & $0.95 \pm 0.22$ & $0.87 \pm 0.16$ \\
\hline C10:0 & $3.40 \pm 0.82$ & $3.31 \pm 0.73$ & $3.00 \pm 0.55$ \\
\hline Total & $5.26 \pm 0.91$ & $5.61 \pm 1.28$ & $5.74 \pm 1.30$ \\
\hline \multicolumn{4}{|l|}{ LCFA } \\
\hline C12:0 & $2.23 \pm 0.42$ & $2.22 \pm 0.36$ & $2.04 \pm 0.30$ \\
\hline C13:0 & $0.05 \pm 0.03$ & $0.05 \pm 0.02$ & $0.05 \pm 0.03$ \\
\hline $\mathrm{C} 14: 0$ & $7.83 \pm 0.89$ & $7.97 \pm 0.91$ & $7.66 \pm 0.74$ \\
\hline C15:0 & $1.08 \pm 0.12$ & $1.08 \pm 0.19$ & $1.11 \pm 0.19$ \\
\hline C16:0 & $21.78 \pm 1.18$ & $21.77 \pm 1.39$ & $22.42 \pm 0.92$ \\
\hline $\mathrm{C} 17: 0$ & $1.03 \pm 0.11$ & $1.01 \pm 0.12$ & $1.02 \pm 0.07$ \\
\hline C18:0 & $11.52 \pm 1.16$ & $12.22 \pm 1.83$ & $11.80 \pm 1.32$ \\
\hline C20:0 & $0.30 \pm 0.04$ & $0.33 \pm 0.06$ & $0.33 \pm 0.05$ \\
\hline Total & $46.41 \pm 2.66$ & $46.64 \pm 1.44$ & $45.79 \pm 1.86$ \\
\hline$\Sigma$ SFA\% & $51.67 \pm 3.03$ & $52.24 \pm 2.29$ & $51.67 \pm 3.04$ \\
\hline
\end{tabular}

SCFA- short-chain fatty acids, LCFA - long-chain fatty acids, SFA - saturated fatty acids; ( $\mathrm{g} / 100 \mathrm{~g}$ of fat). Mean $\pm S D$ values within the same row sharing a different superscript letter $(a, b, c, e t c$.) are significantly different $(P<0.05)$.

Table 7. The content of individual unsaturated fatty acids (UFA) in the milk of the Zošl'achtená valaška sheep for the ANXA9 polymorphisms. a) ANXA9/Nlall; b) ANXA9/Hinfl; c) ANXA9/Tru1I

7 a) 


\begin{tabular}{|llll|}
\hline \multicolumn{3}{|c|}{ ANXA9/NIallI } \\
\hline & AA & GA & GG \\
\hline MUFA & & & \\
\hline C14:1 & $0.55 \pm 0.07$ & $0.58 \pm 0.08$ & $0.56 \pm 0.11$ \\
\hline C16:1 & $5.95 \pm 0.78$ & $5.57 \pm 0.70$ & $5.61 \pm 0.69$ \\
\hline C17:1 & $0.50 \pm 0.02$ & $0.51 \pm 0.07$ & $0.49 \pm 0.06$ \\
\hline C18:1n9c & $21.87 \pm 1.80$ & $22.37 \pm 1.95$ & $22.77 \pm 2.26$ \\
\hline C18:1n9t & $2.03 \pm 0.47$ & $1.85 \pm 0.48$ & $1.82 \pm 0.35$ \\
\hline C18:1n7t & $2.10 \pm 0.29$ & $2.07 \pm 0.26$ & $2.18 \pm 0.28$ \\
\hline C20:1 & $0.08 \pm 0.07$ & $0.07 \pm 0.01$ & $0.08 \pm 0.03$ \\
\hline $\boldsymbol{\Sigma}$ MUFA & $33.06 \pm 1.92$ & $33.01 \pm 1.93$ & $33.50 \pm 2.26$ \\
\hline PUFA & & & \\
\hline C18:2n6c & $1.66 \pm 0.20$ & $1.78 \pm 0.27$ & $1.81 \pm 0.29$ \\
\hline CLA & $1.16 \pm 0.28$ & $1.18 \pm 0.23$ & $1.30 \pm 0.19$ \\
\hline C18:3n3 & $1.45 \pm 0.14$ & $1.54 \pm 0.26$ & $1.48 \pm 0.16$ \\
\hline C20:4n6 & $0.07 \pm 0.04^{\mathrm{A}}$ & $0.11 \pm 0.03^{\mathrm{B}}$ & $0.11 \pm 0.03^{\mathrm{B}}$ \\
\hline C20:5n3 & $0.08 \pm 0.04$ & $0.09 \pm 0.03$ & $0.08 \pm 0.02$ \\
\hline $\boldsymbol{\Sigma}$ PUFA & $4.42 \pm 0.41$ & $4.69 \pm 0.59$ & $4.76 \pm 0.5$ \\
\hline $\boldsymbol{\Sigma}$ UFA & $\mathbf{3 8 . 3 0} \pm 2.51$ & $\mathbf{3 8 . 4 7} \pm 2.12$ & $\mathbf{3 9 . 0 8} \pm 2.58$ \\
\hline
\end{tabular}

MUFA - monounsaturated fatty acids, PUFA - Polyunsaturated fatty acids; (g/ $100 \mathrm{~g}$ of fat). Mean \pm SD values within the same row sharing a different superscript letter $(a, b, c$, etc.) are significantly different ( $P$ $<0.05)$ and the superscript capital letter (A, B, C, etc.) different at $P<0.01$.

7 b) 


\begin{tabular}{|llll|}
\hline \multicolumn{3}{|c|}{ ANXA9/Hinfl } \\
\hline & CC & CG & GG \\
\hline MUFA & & & \\
\hline C14:1 & $0.60 \pm 0.06$ & $0.55 \pm 0.09$ & $0.57 \pm 0.08$ \\
\hline C16:1 & $5.55 \pm 0.70$ & $5.66 \pm 0.72$ & $5.68 \pm 0.71$ \\
\hline C17:1 & $0.51 \pm 0.05$ & $0.50 \pm 0.06$ & $0.49 \pm 0.07$ \\
\hline C18:1n9c & $22.06 \pm 1.75$ & $22.62 \pm 1.98$ & $22.66 \pm 2.44$ \\
\hline C18:1n9t & $1.76 \pm 0.55^{\mathrm{A}}$ & $1.80 \pm 0.40^{\mathrm{a}}$ & $2.02 \pm 0.28^{\mathrm{Bb}}$ \\
\hline C18:1n7t & $2.04 \pm 0.32$ & $2.18 \pm 0.26$ & $2.12 \pm 0.24$ \\
\hline C20:1 & $0.08 \pm 0.02$ & $0.08 \pm 0.04$ & $0.07 \pm 0.03$ \\
\hline $\boldsymbol{\Sigma}$ MUFA & $32.57 \pm 1.88$ & $28.90 \pm 11.63$ & $33.82 \pm 2.16$ \\
\hline PUFA & & & \\
\hline C18:2n6c & $1.79 \pm 0.27$ & $1.79 \pm 0.27$ & $1.75 \pm 0.25$ \\
\hline CLA & $1.21 \pm 0.24$ & $1.0 \pm 0.24^{\mathrm{b}}$ & $1.16 \pm 0.17^{\mathrm{a}}$ \\
\hline C18:3n3 & $1.53 \pm 0.24$ & $1.46 \pm 0.16$ & $1.53 \pm 0.23$ \\
\hline C20:4n6 & $0.10 \pm 0.03$ & $0.11 \pm 0.03$ & $0.09 \pm 0.04$ \\
\hline C20:5n3 & $0.09 \pm 0.02$ & $0.08 \pm 0.02$ & $0.08 \pm 0.03$ \\
\hline $\boldsymbol{\Sigma}$ PUFA & $4.71 \pm 0.66$ & $4.14 \pm 1.72$ & $4.56 \pm 0.51$ \\
\hline $\boldsymbol{\Sigma}$ UFA & $38.03 \pm 2.20$ & $38.95 \pm 2.56$ & $39.00 \pm 2.25$ \\
\hline
\end{tabular}

MUFA - monounsaturated fatty acids, PUFA - Polyunsaturated fatty acids; ( $g / 100 \mathrm{~g}$ of fat). Mean \pm SD values within the same row sharing a different superscript letter $(a, b, c, e t c$.) are significantly different $(P$ $<0.05)$ and the superscript capital letter $(A, B, C$, etc.) different at $P<0.01$.

7 c) 


\begin{tabular}{|llll|}
\hline \multicolumn{5}{|c|}{ ANXA9/Hinfl } \\
\hline & CC & CG & GG \\
\hline MUFA & & & \\
\hline C14:1 & $0.60 \pm 0.06$ & $0.55 \pm 0.09$ & $0.57 \pm 0.08$ \\
\hline C16:1 & $5.55 \pm 0.70$ & $5.66 \pm 0.72$ & $5.68 \pm 0.71$ \\
\hline C17:1 & $0.51 \pm 0.05$ & $0.50 \pm 0.06$ & $0.49 \pm 0.07$ \\
\hline C18:1n9c & $22.06 \pm 1.75$ & $22.62 \pm 1.98$ & $22.66 \pm 2.44$ \\
\hline C18:1n9t & $1.76 \pm 0.55^{\mathrm{A}}$ & $1.80 \pm 0.40^{\mathrm{a}}$ & $2.02 \pm 0.28^{\mathrm{Bb}}$ \\
\hline C18:1n7t & $2.04 \pm 0.32$ & $2.18 \pm 0.26$ & $2.12 \pm 0.24$ \\
\hline C20:1 & $0.08 \pm 0.02$ & $0.08 \pm 0.04$ & $0.07 \pm 0.03$ \\
\hline $\boldsymbol{\Sigma}$ MUFA & $32.57 \pm 1.88$ & $28.90 \pm 11.63$ & $33.82 \pm 2.16$ \\
\hline PUFA & & & \\
\hline C18:2n6c & $1.79 \pm 0.27$ & $1.79 \pm 0.27$ & $1.75 \pm 0.25$ \\
\hline CLA & $1.21 \pm 0.24$ & $1.0 \pm 0.24^{\mathrm{b}}$ & $1.16 \pm 0.17^{\mathrm{a}}$ \\
\hline C18:3n3 & $1.53 \pm 0.24$ & $1.46 \pm 0.16$ & $1.53 \pm 0.23$ \\
\hline C20:4n6 & $0.10 \pm 0.03$ & $0.11 \pm 0.03$ & $0.09 \pm 0.04$ \\
\hline C20:5n3 & $0.09 \pm 0.02$ & $0.08 \pm 0.02$ & $0.08 \pm 0.03$ \\
\hline $\boldsymbol{\Sigma}$ PUFA & $4.71 \pm 0.66$ & $4.14 \pm 1.72$ & $4.56 \pm 0.51$ \\
\hline $\boldsymbol{\Sigma}$ UFA & $\mathbf{3 8 . 0 3} \pm 2.20$ & $\mathbf{3 8 . 9 5} \pm 2.56$ & $\mathbf{3 9 . 0 0} \pm 2.25$ \\
\hline
\end{tabular}

MUFA - monounsaturated fatty acids, PUFA - Polyunsaturated fatty acids; (g/100g of fat). Mean \pm SD values within the same row sharing a different superscript letter $(a, b, c, e t c$.) are significantly different $(P$ $<0.05)$ and the superscript capital letter $(A, B, C$, etc.) different at $P<0.01$.

Furthermore, we estimated the genetic correlations among individual FAs, which were shown in (Table 8 and 9). For two individual SCFA (C4:0, C6:0), and one LCFA (C:14) negative genetic correlations were observed for SCD1/Cfr13I polymorphism and two negative correlation for two LCFA (C15:0, C20:0) over ANXA9/Hinfl polymorphism.

Table 8. Correlation coefficients between the polymorphism in genes and the content of individual saturated fatty acids (SFA) in sheep of milk. 


\begin{tabular}{|llllll|}
\hline & SCD1/Cfr13I & FASN/ACI & ANXA9/NlallI & ANXA9/HinfI & ANXA9/Tru1I \\
\hline SCFA & & & & & \\
\hline C4:0 & $-0.3734^{*}$ & 0.0591 & 0.2211 & -0.1925 & 0.0956 \\
\hline C6:0 & $-0.3742^{*}$ & 0.0375 & 0.2350 & -0.1748 & 0.0042 \\
\hline C8:0 & -0.2999 & 0.0636 & 0.2420 & -0.0920 & -0.0972 \\
\hline C10:0 & -0.2405 & 0.1467 & 0.2453 & -0.0467 & -0.1456 \\
\hline Total & $-0.3192^{*}$ & 0.1145 & 0.2630 & -0.1054 & -0.0846 \\
\hline LCFA & & & & & \\
\hline C12:0 & -0.3043 & 0.1499 & 0.1894 & -0.0476 & -0.1140 \\
\hline C13:0 & -0.0231 & 0.2420 & 0.0153 & -0.1343 & -0.0352 \\
\hline C14:0 & $-0.3670^{*}$ & 0.1308 & -0.0542 & -0.1159 & 0.0153 \\
\hline C15:0 & 0.0536 & 0.2259 & -0.0184 & $-0.3889^{*}$ & 0.1071 \\
\hline C16:0 & -0.0012 & 0.0553 & -0.1496 & -0.1792 & 0.2070 \\
\hline C17:0 & -0.0406 & -0.1041 & 0.0068 & -0.2491 & 0.0516 \\
\hline C18:0 & -0.1226 & -0.0989 & 0.1022 & -0.0513 & 0.0874 \\
\hline C20:0 & -0.0942 & 0.0682 & 0.1736 & $-0.3627^{*}$ & 0.1886 \\
\hline Total & $-0.3288^{*}$ & 0.0635 & 0.0008 & -0.2801 & 0.2082 \\
\hline 区SFA\% & $-0.3808^{*}$ & 0.0975 & 0.1210 & -0.2490 & 0.1096 \\
\hline
\end{tabular}

SCFA- short-chain fatty acids, LCFA - long-chain fatty acids, SFA - saturated fatty acids; (g/ $100 \mathrm{~g}$ of fat). *Significance at $\mathrm{P}<0.05$ was marked by an asterisk.

Positive genetic correlations were observed between MUFA and UFA and SCD1/Cfr13I, although negative correlations for $\mathrm{C} 20: 5 \mathrm{n} 3$ was observed (Table 9). We also showed a positive correlation between C20:4n6 and ANXA9/Nlalll.

Table 9. Correlation coefficients between the polymorphism in genes and the content of individual unsaturated fatty acids (UFA) in the milk of sheep. 


\begin{tabular}{|llllll|}
\hline & SCD1/Cfr13I & FASN/ACI & ANXA9/NlallI & ANXA9/HinfI & ANXA9/Tru1I \\
\hline MUFA & & & & & \\
\hline C14:1 & -0.0424 & 0.3085 & 0.1773 & -0.2766 & 0.1236 \\
\hline C16:1 & 0.2792 & 0.0831 & -0.1110 & 0.1654 & -0.2709 \\
\hline C17:1 & 0.0187 & -0.0681 & 0.0297 & -0.0887 & 0.1980 \\
\hline C18:1n9c & 0.2592 & -0.1532 & -0.0140 & 0.0911 & 0.0871 \\
\hline C18:1n9t & 0.1201 & -0.1344 & -0.1151 & 0.2373 & -0.2861 \\
\hline C18:1n7t & 0.2037 & -0.0119 & -0.1108 & 0.2133 & 0.0356 \\
\hline C20:1 & -0.1999 & 0.0528 & -0.0688 & -0.0076 & -0.0863 \\
\hline $\boldsymbol{\Sigma}$ MUFA & $0.3576^{*}$ & -0.1208 & -0.0717 & 0.1832 & -0.0383 \\
\hline PUFA & & & & & \\
\hline C18:2n6c & 0.0596 & -0.0714 & 0.1185 & -0.0048 & 0.2117 \\
\hline CLA & 0.1565 & 0.0415 & -0.1189 & 0.1366 & 0.0708 \\
\hline C18:3n3 & -0.0284 & -0.2810 & 0.1501 & -0.1931 & 0.1059 \\
\hline C20:4n6 & 0.0232 & 0.1968 & $0.3630^{*}$ & 0.1773 & 0.0994 \\
\hline C20:5n3 & $-0.3164^{*}$ & -0.1220 & 0.1814 & -0.2666 & 0.1570 \\
\hline $\boldsymbol{\Sigma}$ PUFA & 0.0654 & -0.1122 & 0.0952 & -0.0205 & 0.1804 \\
\hline $\boldsymbol{\Sigma}$ UFA & $0.346 *^{*}$ & -0.1348 & -0.0451 & 0.1727 & -0.0089 \\
\hline
\end{tabular}

MUFA - monounsaturated fatty acids, PUFA - Polyunsaturated fatty acids; ( $\mathrm{g} / 100 \mathrm{~g}$ of fat). *Significance at $\mathrm{P}<0.05$ was marked by an asterisk.

\section{Discussion}

Sheep milk is characterized by high variability in the level of fatty acids $25,26,27$. The level of saturated fatty acids (SFA) ranges from 49.43 to $82.9 \mathrm{~g} / 100 \mathrm{~g}$ fat. On the other hand, the share of MUFA and polyunsaturated fatty acids (PUFA) is slightly lower (MUFA: $11.95-45.26 \mathrm{~g} / 100 \mathrm{~g}$ fat, PUFA $2.79-12.24$ $\mathrm{g} / 100 \mathrm{~g}$ fat) ${ }^{26}$. The results obtained in the author's research correspond with the literature data.

Due to the biohydrogenation process taking place in the rumen content, nutrition is the main factor determining the fatty acid profile in the milk of ruminants $10,25,27$. However, the level of fatty acids in sheep milk shows a low to moderate genetic variation for individual acids (ranging from 0.01 to 0.47 ) ${ }^{26}$. Therefore, nutrition and genetics play a key role in modulating the composition of milk fat 25 . 
According to Crisà et al. (2010) ${ }^{9} 257 C T$ (exon 32) polymorphism in the $F A S N$ gene significantly affects the level of the following acids in sheep milk: C10:0; C10:1, C12:0; C14:0; C15:0; C17:1. On the other hand, other authors found the effect of the FASN gene polymorphism (SNP was mapped in intron 31) also on the C13:0 level in sheep milk ${ }^{28}$. However, it is the T allele in FASN that is responsible, at least in part, for a higher level of fatty acids in milk ${ }^{9}$. In our research, the FASN polymorphism affected no changes in the fatty acid composition in milk, which may be related to the low share of the T allele in the sheep genotype.

Studies by other authors have shown a link between polymorphisms (other than those studied in the present work) of the SCD1 gene and the composition of fatty acids in ruminant products, including sheep milk. They found that the analyzed SNPs in SCD1 significantly influenced the level of C16:1 acid, C18:1 trans-11 acid, the content of SFA and MUFA in sheep milk ${ }^{29}$. Moreover, Gu et al. (2019) ${ }^{30}$ analyzed the polymorphism in the promoter region of the $S C D 1$ gene (g.133A>C) showed that the presence of the C allele results in higher levels of MUFA and lower levels of SFA. In our study we found, that the milk of the homozygous $C C$ sheep contains a higher level of $\mathrm{C} 20: 1$ and $\mathrm{C} 20: 5 \mathrm{n} 3$ acids for the milk of sheep with $A A$ genotype. In the case of SFA and MUFA, a higher share of MUFA and a lower share of SFA were obtained in the milk of the homozygous $A A$ sheep. The presence of features linked to polymorphism is related, among others, to the specificity of population and animal species ${ }^{31}$, which may explain the obtained results.

There are only a few studies in the available literature describing the effect of $S C D 1^{29}$ and $A N X A 9$ polymorphisms on the composition of sheep milk, including the fatty acid profile. The polymorphism in the $A N X A 9$ gene affects the yield of milk fat in cows ${ }^{32}$ and the level of fat in sheep milk ${ }^{7}$. The authors' research revealed the effect of SNP in the $A N X A 9$ gene on the share of the following acids: C15:0; C18:0; C20:0 and C18:19t; C20:4n6; and CLA.

In the human diet, foods with a low n-6/n-3 share, ranging from $1: 1$ to $4: 1$, are desirable ${ }^{33}$. Maintaining a sufficiently low $n-6 / n-3$ ratio in the diet has a positive effect on the cognitive functions of the body and reduces the risk of depression ${ }^{34}$. Additionally, the high consumption rate of $(n-3) /(n-6)$ PUFAs reduces the risk of neoplastic diseases and inflammations $2,33,35$.

In the case of the $S C D 1 / C f r 13$ polymorphism, an increase in C20:5n3 was observed in milk of the sheep with homozygous $C C$ genotypes, without changes in the level of $n-6$ acids, which may cause an increase in the value of $(n-3) /(n-6)$. In the case of $A N X A 9 / N / a l l l$ polymorphism analysis for $A A$ homozygous animals, a decrease in the $\mathrm{C} 20: 4 \mathrm{n} 6$ acid level was found, which can also be considered a favourable phenomenon. Supplementation of CLA in the diet of animals and humans improves the metabolism of glucose and lipids in the body ${ }^{36}$. In our research, an increase in the level of CLA in the milk of sheep with the GG ANXA9/Hinfl genotype was observed.

According to studies by other authors, long-chain unsaturated fatty acids are important in the human diet 33,35,36. Replacing SFA with PUFA in the human diet is beneficial for the cardiovascular system ${ }^{37}$. In the 
diet, saturated acids, such as C18:0, C14:0 and C12:0, adversely affect the increase of plasma lipoproteins ${ }^{38}$. On the other hand, the consumption of saturated fatty acids with a carbon chain from C12 to $\mathrm{C} 16$ increases the level of plasma LDL-C ${ }^{37,39}$. In our research, an increase in the level of C18:0 acid was noted in the $A N X A 9 /$ Hinfl polymorphism in the homozygous GG individuals, while in the homozygous AA sheep, in the case of the SCD1/Cfr13I polymorphism, a decrease in the level of C12:0, C13:0, C14:0 acids and an increase in MUFA level in milk was observed. Consuming MUFA has a positive effect on humans, reduces total cholesterol and LDL fraction in the blood ${ }^{40}$.

The share of individual fatty acids in the human diet determines both physical and mental health. The present study determined the relationship between the studied polymorphisms and the fatty acid profile in milk and the results may be used in the selection program in sheep flocks: the choice of an appropriate genotype variant will ensure the desired fatty acid profile in milk.

\section{Conclusions}

The research was aimed at searching for the best marker influencing the fatty acid profile in sheep milk. These preliminary findings show that the greatest changes were observed in sheep with $S C D 1 / C f r 13$ I polymorphism and the least significant ones in FASN/ACl. Milk obtained from the homozygous $A A$ sheep (SCD1/Cfr13I) had the best fatty acid profile. Slight changes in the milk of sheep were found for polymorphisms in the ANXA9 gene. For the ANXA9/Nlalll polymorphism ( $A A$ genotype animals) a favourable reduction in the level of $\mathrm{C} 20: 4 \mathrm{n} 6$ acid in the milk was noted. Changes were also found for the ANXA9/Hinfl polymorphism (homozygous $G G$ individuals). The milk of these sheep was characterized by an increase in the level of C18:1n9t and CLA acids, which is beneficial; unfortunately, an undesirable increase in the proportion of $\mathrm{C} 18: 0$ acid was also found. Because presented results indicate the association of the analyzed genotypes with the fatty acid profile in Zošl'achtená valaška, a larger prospective study will be continued to explore the effect of SNPs, also in the other genes showing effects on sheep milk. Moreover, results of our study can be useful for breeders, especially that Zošl'achtená valaška sheep are included in the breeding program and sheep with homozygous $A A(S C D 1 / C f r 131)$ could be used during the breed improvement program.

\section{Declarations}

Ethical statement. All methods and procedures strictly complied with the "Regulation on the Studying Procedures and Principles of Animal Experiments of Ethics Committees" and were approved by the Veterinary Care of the University of Veterinary Medicine and Pharmacy in Košice, permission number IČo 003974742015 , licensed by the Ministry of Education, Sciences, Research and Sport of the Slovak Republic All animals used in this study were handled in strict accordance with good clinical practices following EU legislation (Council Directive 2010/63/EU), and all efforts were made to minimize suffering.

Author Contributions: Conceptualization, E.P.-K. and I.K.t.; investigation, E.P.-K and I.K.t.; Analyzed the data E.P.-K., I.K.Ł., E.C.-P, B.K.; writing the first version of the manuscript, E.P.-K., I.K.-Ł., E.C.-P.; prepared 
revision B.K., E.P.-K. All authors approved the final version of the manuscript.

Conflicts of Interest: The authors declare no conflicts of interest.

\section{References}

1. Chen, J. \& Liu , H. Nutritional indices for assessing fatty acids: A mini-review. J. Mol. Sci. 21, 5695. https://doi.org/10.3390/ijms21165695 (2002).

2. Zhang, X. et al. Fatty acid composition analyses of commercially important fish species from the Pearl River Estuary, China. PlosOne. https://doi.org/10.1371/journal.pone.0228276 (2020).

3. Astrup, A. et al. Yusuf, R.D.S., Krauss, R.M. Saturated fats and health: a reassessment and proposal for food-based recommendations: state-of-the-art review. JACC. 76, 844-857. https://doi.org/10.1016/j.jacc.2020.05.077 (2020).

4. Cividini, A. \& Simčič, M. Fatty acid profile in milk of Bovec sheep fed in the stable or grazed in different pastures. 21, 109-112. DOI: 10.18047/poljo.21.1.sup.25 (2015).

5. Ganter, Mijić, P., Baban, M., Škrtić, Z. \& Turalika, A. The overall and fat composition of milk of various species. Mljekarstvo. 65, 223-231. DOI: 10.15567/mljekarstvo.2015.0401 (2015).

6. Pecka, E., Zachwieja, A. \& Tumanowicz, J. Technological parameters of milk depending on the cow housing system, nutrition system, age, and number of somatic cells. Przemyst Chemiczny. 92, 10871091 (2013).

7. Pecka-Kiełb, E., Czerniawska-Piątkowska, E., Kowalewska-tuczak, I. \& Vasil, M. Polymorphism in ovine ANXA9 gene and physic-chemical properties and the fraction of protein in milk. Sci Food Agric. 98, 5396-5400. doi:10.1002/jsfa.9081(2018).

8. Zidi, A. et al. Association between the polymorphism of the goat stearoyl-CoA desaturase 1 (SCD1) gene and milk fatty acid composition in Murciano-Granadina goats. J Dairy Sci. 93, 4332-9. doi: 10.3168/jds.2009-2597 (2010).

9. Crisà, A. et al. Exploring polymorphisms and effects of candidate genes on milk fat quality in dairy sheep Dairy Sci. 93, 3834-3845. doi: 10.3168/jds.2009-3014 (2010).

10. Urrutia, O. et al. Adipose tissue modification through feeding strategies and their implication on adipogenesis and adipose tissue metabolism in ruminants. Int. J. Mol. Sci. 21, 3183; https://doi.org/10.3390/ijms21093183 (2020).

11. Chirala, S.S. et al. Fatty acid synthesis is essential in embryonic development: Fatty acid synthase null mutants and most of the heterozygotes die in utero. Proc Natl Acad Sci U S A. 100, 6358-6363 doi/10.1073/pnas.0931394100 (2003).

12. Calvo, J.H. et al. Isolation, mapping, and identification of SNPs for four genes (ACP6, CGN, ANXA9, SLC27A3) from a bovine QTL region on BTA3. Cytogenetic Genome Res. 114, 39-43. DOI: 10.1159/000091926 (2006). 
13. Mele, M. et al. Stearoyl-coenzyme A desaturase gene polymorphism and milk fatty acid composition in Italian Holsteins. Dairy Sci. 90, 4458-4465, https://doi.org/10.3168/jds.2006-617 (2007).

14. Barton, L. et al. The polymorphisms of stearoyl-CoA desaturase (SCD1) and sterol regulatory element binding protein-1 (SREBP-1) genes and their association with the fatty acid profile of muscle and subcutaneous fat in Fleckvieh bulls. Meat Sci. 85, 15-20. doi: 10.1016/j.meatsci.2009.11.016. (2010).

15. Ferro, M. M., Tedeschi, L. O. \& Atzori, A. S. The comparison of the lactation and milk yield and composition of selected breeds of sheep and goats, Translational Animal Science. 1, 498-506 (2017).

16. Czerniawska-Piątkowska, E., Kowalewska-tuczak, I., Pecka-Kiełb, E. \& Banaszewska, D. Effects of FASN and SCD gene polymorphism on the composition of sheep's milk. JAPS. 31, 906-912. https://doi.org/10.36899/JAPS.2021.3.0280 (2021).

17. Kowalewska-Łuczak, I., Czerniawska-Piątkowska, E. \& Pecka-Kiełb, E. Investigation on relationships of the FABP3 AND SLC27A3 genes with milk production traits in sheep. Elementol. 22, 1485-1493. doi:10.5601/jelem.2017.22.1.1406 (2017).

18. Chrenek, P., Makarevič, A., Kubovičová, E., Bulla, J. \& Supuka, P. Slovak national animal breeds; Slovak University of Agriculture in Nitra. Nitra, Slovakia, pp. 1-100 (2019).

19. Christie, W. \& William, S. Lipid analysis. Isolation, separation, identification, and structural analysis of lipids. The isolation of lipids from tissues. Pergamon Press: Oxford, UK, pp. 39-40 (1973).

20. Christopherson, S.W. \& Glass, R.L. Preparation of milk fat methyl esters by alcoholysis in an essentially nonalcoholic solution. Dairy Sci. 52, 1289-1290. doi:10.3168/jds.S0022-0302(69)867391 (1969).

21. Yeh, F.C., Yang, R.T.J. \& Xiyan, J.M. PopGene32. Microsoft Window-based Freeware for Population Genetic Analysis, Version 1.32 (Software). University of Alberta, Edmonton, AB (2000).

22. Kimura, M. \& Crow J. F. The number of alleles that can be maintained in a finite population. Genetics. 49, 725-738 (1964).

23. Nei, M.\& Roychoudhury, A.K. Sampling variances of heterozygosity and genetic distance. 76, 379-390 (1974).

24. Botstein, D., White, E.L., Skolnick, M. \& Dawis, R.W. Construction of a genetic linkage map in man using restriction fragment length polymorphism. J. Hum. Genet. 32, 314-331 (1980).

25. Bastin, C., Gengler, N. \& Soyeurt, H. Phenotypic and genetic variability of production traits and milk fatty acid contents across days in milk for Walloon Holstein first-parity cows. Dairy Sci. 94, $4152-$ 4163. https://doi.org/10.3168/jds.2010-4108 (2011).

26. Correddu, F. et al. Genetic parameters of milk fatty acid profile in sheep: comparison between gas chromatographic measurements and Fourier-transform IR spectroscopy predictions. 13, 469-476. https://doi.org/10.1017/S1751731118001659 (2019).

27. Nudda, A. et al. Feeding strategies to design the fatty acid profile of sheep milk and cheese. Bras. Zootec. 43, 445-456. https://doi.org/10.1590/S1516-35982014000800008 (2014). 
28. Symeou, S., Tzamaloukas, O., Banos, G. \& Miltiadou, D. ACAA2 and FASN polymorphisms affect the fatty acid profile of Chios sheep milk. JDR. 87, 23-26. https://doi.org/10.1017/S0022029919000992 (2020).

29. García-Fernández, M., Gutiérrez-Gil, B., García-Gámez, E.; Sánchez, J.P. \& Arranz, J.J. Detection of quantitative trait loci affecting the milk fatty acid profile on sheep chromosome 22: Role of the stearoyl-CoA desaturase gene in Spanish Churra sheep. Dairy Sci. 93, 348-357. doi: $10.3168 /$ jds.2009-2490 (2010).

30. Gu, M. et al. The single nucleotide polymorphism g.133A>C in the stearoyl CoA desaturase gene (SCD) promoter affects gene expression and quali-quantitative properties of river buffalo milk. Dairy Sci. 102, 442-451. https://doi.org/10.3168/jds.2018-15059 (2019).

31. Palombo, V. et al. Genome-wide association study of milk fatty acid composition in Italian Simmental and Italian Holstein cows using single nucleotide polymorphism arrays. Dairy Sci. 101, 11004-11019. https://doi.org/10.3168/jds.2018-14413 (2018).

32. Martínez-Royo, A. et al. The bovine annexin 9 gene (ANXA9) is significantly associated with milk-fat yield in a Spanish Holstein-Friesian population. Res Vet Sci. 88, 452-455.

https://doi.org/10.1016/j.rvsc.2009.12.009 (2010).

33. Balić, A., Vlašić, D., Žužul, K., Marinović, B. \& Mokos, A.B. Omega-3 Versus Omega-6 Polyunsaturated Fatty Acids in the Prevention and Treatment of Inflammatory Skin Diseases. Int J Mol Sci. 21, 741. doi: 10.3390/ijms21030741. (2020).

34. Layé, S., Nadjar, A., Joffre, C.\& Bazinet, R.P. Anti-inflammatory effects of omega-3 fatty acids in the brain: physiological mechanisms and relevance to pharmacology. Rev. 70, 12-38. doi: 10.1124/pr.117.014092 (2017).

35. Goodstine, S.L et al. Dietary (n-3)/(n-6) fatty acid ratio: possible relationship to premenopausal but not postmenopausal breast cancer risk in U.S. women. J Nutr. 133, 1409-1414, https://doi.org/10.1093/jn/133.5.1409 (2003).

36. Martín-González, M.Z et al. Beneficial effects of a low-dose of conjugated linoleic acid on body weight gain and other cardiometabolic risk factors in cafeteria diet-fed rats. Nutrients. 12,408 . doi: 10.3390/nu12020408 (2020).

37. Siri-Tarino, P.F., Chiu, S., Bergeron, N. \& Krauss, R.M. Saturated fats versus polyunsaturated fats versus carbohydrates for cardiovascular disease prevention and treatment. Rev. Nutr. 35, 517-543. doi:10.1146/annurev-nutr-071714-034449 (2015).

38. Karupaiah, T., Tan, C.H., Chinna, K. \& Sundram, K. The chain length of dietary saturated fatty acids affects human postprandial lipemia. J Am. Coll Nutr. 30, 511-21. DOI: 10.1080/07315724.2011.10719997 (2011).

39. Mensink, R.P., Zock, P.L., Kester, A.D. \& Katan, M.B. Effects of dietary fatty acids and carbohydrates on the ratio of serum total to HDL cholesterol and on serum lipids and apolipoproteins: A metaanalysis of 60 controlled trials. J. Clin. Nutr. 77, 1146-55. doi:10.1093/ajcn/77.5.1146 (2003). 
40. Gill, J. et al. Effects of dietary monounsaturated fatty acids on lipoprotein concentrations, compositions, and subfraction distributions and on VLDL apolipoprotein B kinetics: dose-dependent effects on LDL. Am J Clin Nutr. 78, 47-56 doi: 10.1093/ajcn/78.1.47 (2003). 